illustrated it were particularly good, which, sering that Mr. Bedford began his work in this direction so long ago as 1890 , is not, perhaps, to be wondered at.

The last lecture, on Saturday morning, June 9, to which the teachers of the district were invited, was given by Mr. Wilfred Mark Webb, on nature-study. As two years ago $\mathrm{Mr}$. Webb presented a formal paper to the union, he contented himself, after a few brief remarks, with showing by means of lantern-slides what directions the pursuit in question has taken or might take.

A number of interesting specimens were brought together to form the usual congress museum under the direction of Mr. F. IV. Swanton, and the photographic survers of Surrey, Kent, and Sussex contributed a sfilection of photographs.

The business done included the election of Prof. Silvanus Thompson as president for $190 \%$, and the acceptance of an invitation to visit Woolwich for the twelfth congress in that vear. Dr. Abbott, the founder of the union, its first secretary and late treasurer, was added to the list of vice-presidents, of whom besides Dr. Hutchinson, Mr. F. Merrifield, Mr. F. IV. Rudler, the Rev. T. R. R. Stebbing, Dr. Treutler, and Mr. WV. Whitaker attended the congress.

The perfect weather made the four excursions to Mickleham Priory and elsewhere a complete success, and a pleasing feature of the meeting was the rotes of thanks to local secretaries, Mr. J. J. Hollway and Mr. Sparks, and their coadjutors, as well as that to the general secretary, the Rev. R. Ashington Bullen, which was emphasised by the whole company rising in their seats.

\section{THE SURFACE TRAJECTORIES OF MOVING} $A I R .^{1}$

THE Meteorological Office has just published the resuits of an investigation into the movements of the air during storms and periods of barometric depression affecting the North Atlantic and western Europe. The authors deal, not so much with the discussion of theories about cyclones as with the results of direct observations on the direction and force of the winds as recorded at as many stations and as often as possible. Apart from ships' logs, the records from about 200 stations have been utilised.

The attempt has been made to trace the path of any body of air from the point where it descended from the upper regions of the atmosphere along the surface of the earth to the place where it ascended again, and the method used is briefly as follows:--lising hourly observations whenever possible, arrows have been drawn on a map through the position of the recording station showing the direction of the wind, and the length of the arrow is equal to the distance which the recorded velocity suggests as being the journey of the air during the half-hour preceding and the half-hour following the time of observation. By this method the trajectories are made up step by step through station after station as the hourly maps are made up. Anemoneter records are consulted to decide where the velocity of the wind has been sufficiently constant to carry the trajectory properly from one hour to the next.

In the discussion of rertain circular storms and barometric depressions which have passed over the British Isles, and which have been selected as typical examples, I $6_{2}$ trajectories were exanined, and also the changes in the meteorological conditions along them. Naturally many of these trajectories do not represent the full course of the particular current considered, only the beginning, the middle or the end coning within the region under observation.

These irajectories have been divided into five classes. Class i.--Final-stage trajectories terminating generally, but not always, near the centre or the troush of the depression. These are marked by diminishing pressure, in-

1 "The Iife-history of Surface Air-currents; a Study of the Surface Trajertories of Moving Air." By Dr. W. N. Shaw, F.R.S., and R. G. K. I,empfert. (I,ondon: Published hy the Authority of the Meteorological Committee, Wyman and Sons, Lid.) P'rice $7 s .6 d$.

$$
\text { NO. I } 9 \text { I I, VOL. 74] }
$$

creasing velocity, and falling temperature. These currents end under cloudy skies and with rainfall. In some cases the end is caused by the meeting with a cross-current. The conclusion is that this air has fed the ascending current, and that the rain has been caused by the expansion and consequent cooling. These trajectories are always from almost due south, and show very little curvature.

Class ii.--Initial-stage trajectories, commencing in regions of fairly still air which may be quite near to the centre of the depression. The meteorological conditions and changes which characterise this class are the reverse of those for class $i$., even to this extent, that they flow from low pressure to high. There are many cases of this class shown; too many to suggest a mistake.

Class iii.--Looped trajectories generally cross the track of the depression twice, once in front of the storm and once behind, and may be taken as a continuation of classes $\mathrm{i}$. and ii.

Class iv.-Spiral trajectories generally represent cold currents blowing from the east or north round the west of the centre of the depression to replace the southerly currents of class $i$.

Class v. has three subsections:-(a) trajectories from a point in front of the trough; $(b)$ from a point in the rear; and $(c)$ in the line of the trough. The meteorological conditions accompanying $(a)$ and $(b)$ are similar to those for classes $i$. and ii. Trajectories in the line of the trough are remarkable for the strength of the wind and for the small and irregular changes of pressure. The accompanying weather is generally cloudy, but without rain.

'The trajectories over the Atlantic are obtained from observations made between August, I882, and September, $\mathrm{I} 88_{3}$, and, as only daily records are used, the investigation is on a much coarser scalc. Moreover, they are more open to criticism, for there may be many changes in the meteorological elements in twenty-four hours. Some of the trajectories traced are remarkable for their length; for example, between December 23 and 30,1882 , one is traced from West Africa to North Russia, and another from Florida to the British Isles, and between November 13 and 17 one is followed from lludson's Bay to the Adriatic.

In secking to locate the positions of ascending and descending currents and the connection between these and the distribution of rainfall, it has been taken as proved that an ascending current of air is necessary for the production of measurable rainfall, and we are reminded that it is not necessary or usual for these ascending or descending currents to be vertical. They are generally very oblique. The approximate positions of ascending currents are located by notings the convergence of air to such places, divergence denoting descension.

Conversence may be produced by the trajectories being directed towards one point, or by air overtaking air which is preceding it in the same direction, or by the wind blowing towards a persistent cross-current. These are obvious and typical cases.

If two sets of isochronous points or trajectories be joined by lines, then the ratios of the enclosed areas will indicate convergence or divergence according to whether the second area is smaller or larger than the first.

The greater convergence takes place almost always in front of the centre of the depression, and this agrees with the area of greatest rainfall. As, however, the rain is generally brought by southerly winds, the rainy district is somewhat to the north of the area of convergence. the current evidently having continued its onward course whilst rising.

Some of the general conclusions deduced during the investigation may be given :-

(1) In the front portion of travelling storms there is air moving from high pressure to low and to lower temperature and rainfall, while in the rear, even quite close to the centre, there is movement from low pressure to high and towards improving weather conditions.

(2) Fast-travelling storms receive air from the right hand (south) of the path in front of the storm, and lose an equivalent amount from the rear at the same side. Slow-travelling storms receive air from the south direct to 
the centre, whilst air from the north flows round the rear.

(3) Southerly winds are generally short-lived as surface currents. Other currents last longer. They may persist until they reach the trade winds, or they may turn and join the depression from the south, or may disappear in some depression over the Atlantic.

(4) The central areas of well-marked anticyclones have not shown themselves to be the usual birthplace of descending currents. These generally originate in the "col" or shoulder of an anticyclone, or the areas of comparatively low pressure between two anticyclonic or two cyclonic areas. Only very rarely has a trajectory been traced back to the centre of an anticyclone.

(5) Surface observations have not indicated the conditions which mark out the track of a barometric minimum.

The publication contains some twenty-six valuable plates of weather charts with the trajectories plotted, and accompanied by full notes and selected observations along the trajectories. The trajectories have also been drawn having regard to the centre of the storm as a fixed point. Therc are also some mathematical notes by $\mathrm{Mr}$. G. T. Bennett with reference to looped trajectories and the calculation of dilatation of areas in travelling storms.

W. M.

\section{NEW ARCTIC EXPEDITIONS.}

THE present season promises to be one of unusual importance in the annals of Arctic exploration, both in the way of scientific investigation of specific problems such as those stated in the paper by Sir Clements Markhan published in the January number of the Geographical Journal, and in what may be more correctly described as "attacks on the Pole."

According to a note in the current number of the Geographical Journal, Mr. A. H. Harrison's expedition reached Herschel Island, near the mouth of the Mackenzie, in February last, where Mr. Harrison found Lieut. Hansen and the members of the Gjöa expedition. Writing on March $\mathrm{x}, \mathrm{Mr}$. Harrison expressed the intention of making his way during April to Bailie Island, and thence to Banks Land, where he proposes to spend next winter.

The general scheme of the expedition-now formally designated the "Anglo-American" Polar Expeditionundertaken by Mr. Elnar Mikkelsen and Mr. Leffingwell, has already been outlined in these columns (January 25 , vol. Ixxiii., p. 302). Since his arrival in the United States the American Geographical Society has voted Mr. Mikkelsen a sum of 3000 dollars, the largest grant ever given to an explorer by the society, and the council of the Royal Geographical Society has made a second grant of Iool. Mr. Mikkelsen has purchased a schooner of 66 tons burden, which he has named the Duchess of Bedford, and has now been able to elaborate his plans in considerable detail on the lines already announced (see the Times, April 2I, and the Geographical Journal, vol. xxvii., p. 507). The programme is an extensive and extremely hazardous one, but if even a part of it is successfully carried out scientific results of great value will certainly be obtained.

The Danish or "Danmark" expedition, for which funds amounting to about $250,000 \mathrm{kr}$. have been raised by means of a Government grant and private subscriptions, will leave Copenhagen on July I under the leadership of $\mathrm{Mr}$. L. Mylius-Erichsen, and make its way so far north as possible along the east coast of Greenland. There a landing will be effected, and the party will proceed along the east coast, wintering en route, to the most northerly point of Greenland, which is, in the leader's opinion, the most favourable place from which to make an attempt to reach the Pole. A sledge expedition will set out for the Pole from here, and return in time to winter on the ship the second year. In March, I908, Mylius-Erichsen, accompanied by one of his staff and two Greenlanders, hopes to set out on the second part of his journey, and realise the daring plan of traversing the inland ice of Greenland on the broadest portion of the continent. The crossing is to be effected partly by motor-car, partly by dog sledges, and partly on NO. I 9 I I, VOL. 747 ski, and is expected to occupy about two months and a half.

Mr. Walter Wellman has formed a project for reaching the North Pole by means of an airship. The vessel is to start from a base in Spitsbergen, and it is estimated that the return voyage of $\mathrm{I} 200$ miles may be accomplished in from five to fifteen days. This expedition is being financed by $\mathrm{Mr}$. Victor Lawson, chief proprietor of the ChicagoRecord Herald, and a very full description of the airship - which is of a quite novel type-is given by Mr. Wellman in the April number of the National Geographic Magazine. The contract for construction was given to $M$. Louis Godard, of St. Ouen. According to a Reuter correspondent in the Times of June 5, the ship will leave Paris for Spitsbergen in a few days.

\section{A CATALOGUE OF FOSSIL INVERTEBRATES. ${ }^{2}$}

THIS catalogue of fossil invertebrates, compiled by $\mathrm{Mr}$. Charles Schuchert, assisted by Messrs. W. H. Dall, T. W. Stanton, and R. S. Bassler, is arranged alphabetically, and gives the catalogue-number of the department registers, the name of the species as written in the work cited, the kind of type (for instance, holotype, cotype), the formation, locality, author, and place of publication, with remarks on the present name if different from the one cited, or a cross reference when the same species appears in the list under more than one name. Remarks, together with sources of such, are added in brackets where necessary.

The list itself is preceded by an admirably clear and carefully written introduction by $\mathrm{Mr}$. C. Schuchert, dealing mainly with type terms. Use is made of the contributions of Schuchert, Buckman, Cossmann, Oldfield Thomas, Bather, and others to the discussion of the terminology of type specimens, thus furnishing a valuable and concise summary of definitions, the understanding of which is necessary for the proper appreciation of the catalogue. In addition to terms already in use are others which are introduced here for the first time, and consequently call for brief notice. Primary types or proterotypes are divided into holotypes, cotypes (or syntypes), paratypes, lectotypes, and chirotypes, the last two terms being new. The term " chirotype" is proposed for "the material upon which a published manuscript name is based." In cases " where the original diagnosis is without illustrations or is accompanied by figures based on two or more specimens, the first subsequent author is at liberty to select from these cotypes a type for the old species, adhering, as far as can be ascertained, to the intention of the original author." Such a type specimen is designated a "lectotype." Supplementary types are divided into plesiotypes, neotypes, and heautotypes. "Heautotype" is a new term proposed by Buckman for " a specimen figured by an author as an illustration of his own already founded species, such not being a proterotype." Typical specimens are divided into " topotypes," " metatypes," " homœotypes," and "ideotypes "(new). The term "ideotype" is used by Buckman for specimens which come from places other than the original locality, and named by an author of a species after publication. The term " protograph" (suggested by Buckman for the original figure or figures illustrating a holotype) and "synthetograph" (a drawing which is a composite figure based upon several specimens of the new species) are also introduced here for the first time. For any artificial specimen moulded directly from a primary type Schuchert proposes the term "plastotype." For types of genera or genotypes the word "geno" is prefixed to the primary type terms, thus giving the corresponding terms " genoholotype," "genosyntype," and " genolectotype."

We cannot but feel grateful to Mr. Schuchert for his clear correlation of type terms. Although distinctly opposed to a multiplicity of terms in itself, we feel certain that such as are introduced in this volume justify their usage in the interest of scientific method.

I. T.

1 Smithsonian Institution: Bulletin of the United States National Museum ; Catalogue of Fossils, Minerals, Rocks, \&c., Merrill. Part i., Fossil Invertebrates. Pp. 7.04. 